\title{
The Lessons of the Churn: Adult Basic Education and Disciplining the Adult Learner
}

\author{
Erik Jacobson, Montclair State University
}

\begin{abstract}
Each year in the United States, hundreds of thousands of people enroll in adult basic education (ABE) classes but leave before completing a level or accomplishing their goals. The persistence of this phenomenon may indicate that it is a feature of the system, rather than an unforeseen outcome. Research on other types of social service provision (e.g., welfare) suggests that seemingly inefficient systems are actually intentionally constructed to discipline the population in need of assistance. From this perspective, learners' experience of the churn within the ABE system may be just as important as their time in the classroom.
\end{abstract}

Keywords: welfare, homelessness, participation, access, supports

Each year in the United States, hundreds of thousands of people enroll in adult basic education $(\mathrm{ABE})$ classes funded by the federal government only to leave before completing a level or accomplishing the goals that they had set for themselves. This creates an educational churn, a disruptive and disorienting process by which large numbers of people move in and out of a system to what seems like no productive end. In fact, levels of adult literacy in the United States have not changed in decades despite the work of adult education teachers, tutors and program administrators. Moreover, the persistence of this churn may indicate that it is a feature of the system, rather than an unfortunate or unforeseen outcome. Indeed, research on other types of social service provision (e.g., welfare, housing) suggests that seemingly counterproductive or inefficient systems are actually intentionally constructed to discipline and regulate the behavior of the populations in need of assistance (Piven \& Cloward, 1993; Willse, 2015). If that is also the case with regards to $\mathrm{ABE}$, attempts to improve literacy outcomes by continuing to focus on learner or classroom-level factors will necessarily have a limited impact. If our goal is to improve literacy levels at the societal level, the nature and functioning of the $\mathrm{ABE}$ system itself needs to be evaluated, rather than the efforts of individual learners and their teachers.

\section{Re-Examining the Performance of the ABE System in the United States}

Assessments of the impact of the ABE system in the United States have been conceptualized in a number of different ways. Currently, the most prominent accountability measure is the National Reporting System (NRS) for Adult Education which requires states to report the performance 
of programs that receive funding as part of the Workforce Improvement and Opportunity Act (WIOA). Programs and states must provide data regarding students' ability to meet certain goals. These include educational gain, high school completion, entry into post-secondary education or training, gaining employment and retaining employment (U.S. Department of Education, Office of Career, Technical, and Adult Education [OCTAE], 2015). The data is collected and made available in annual reports that contain state by state results and cumulative statistics for the country. These reports note what percentage of students achieved their stated goals and whether or not that constitutes an improvement from previous years. Within the last five reports available (e.g., OCTAE, 2015, 2016, 2018a, 2018 b, 2018c) results vary by no more than a few percentage points. For example, in 2015-2016, 41\% of students whose goal was to complete at least one ABE/ASE functioning level did so, compared to $42 \%$ in 2013-2014. A narrative summary reviews the outcomes for each of the designated goals and suggests what the results mean about the performance of the system and the programs that it funds.

Smaller attempts to evaluate the impact of the ABE system in the United States have been conducted since the 1970s. Rather than focusing on the five set goals of the NRS, these studies have looked for a variety of outcomes. In Beder's (1999) survey of these assessments, potentially relevant outcome measurements included selfesteem (Merrifield, Smith, Rea, \& Shriver, 1994), involvement in children's education (St. Pierre, 1993) and community participation (Becker, Wesselius, \& Fallon, 1976). These early studies have been followed by ones that look for changes in learners' literacy practices rather than changes in academic level or test results (Purcell-Gates, et al., 2002; Reder, 2009), suggesting that the potential value of $A B E$ can be measured by looking at the ways that adults use literacy in their lives. Reder (2009) in particular argues that the impact of program participation may be seen over longer durations, and thus the short-term measurements that the NRS relies upon may not be appropriate.

Despite their differences, these varying approaches all attempt to measure the potential impact of ABE by examining outcomes for students in programs. In the case of the NRS, the focus is on what types of outcomes individuals typically experience. In the case of studies that examine individual learning trajectories, the focus is what types of literacy practices may be associated with program participation (either in the short or long term). Rather than looking to outcomes for the average learner, a different approach to the question of the performance of the $\mathrm{ABE}$ system would be to look more closely at the structure itself. For example, what is the broader impact on society at large? Whose needs are being met? How efficiently and equitably are resources being allocated? What do participation patterns suggest about the nature of program access and support?

The NRS reports themselves provide evidence that participation patterns are indeed an issue. In addition to sharing data on what percentage of students met the prioritized goals, there is data about the following: the number of students who stayed in the program and advanced to the next level, the number of students who remained in the program at the same level, the number that completed a level and left the program and those that left the program without advancing a level. Unlike the other outcome goals, there is no discussion of these statistics in the narrative summary, and the federal totals are only provided at the end of 
the document, after the individual state reports. The table below summarizes data from 2010 to 2016 (e.g., OCTAE, 2015, 2016, 2018a, 2018b, 2018c). Reports prior to 2010-2011 represented this data with bar charts and did not provide raw numbers. The data from 2015-2016 comes from the latest full report. The percentages are not provided in the report itself.

National Level NRS Outcomes - $2010-2016$
\begin{tabular}{c|c|c|c|c|c|c|c|c|c|} 
Year & $\begin{array}{c}\text { Advanced } \\
\text { to Next } \\
\text { Level }\end{array}$ & $\begin{array}{c}\text { Remained } \\
\text { in Same } \\
\text { Level }\end{array}$ & $\begin{array}{c}\text { Completed } \\
\text { Level and } \\
\text { Separated }\end{array}$ & $\begin{array}{c}\text { Separated } \\
\text { Without } \\
\text { Advancing }\end{array}$ & Total & $\begin{array}{c}\text { \%Adv. to } \\
\text { Next } \\
\text { Level }\end{array}$ & $\begin{array}{c}\text { \%Rem. in } \\
\text { the Same } \\
\text { Level }\end{array}$ & $\begin{array}{c}\text { \%Complete } \\
\text { and Leave }\end{array}$ & $\begin{array}{c}\text { \%Separate } \\
\text { Without } \\
\text { Advancing }\end{array}$ \\
\hline $2010-2011$ & 517,298 & 491,035 & 343,972 & 659,858 & $2,012,163$ & $25.71 \%$ & $24.40 \%$ & $17.09 \%$ & $32.79 \%$ \\
\hline $2011-2012$ & 487,639 & 431,568 & 309,807 & 589,792 & $1,818,806$ & $26.81 \%$ & $23.73 \%$ & $17.03 \%$ & $32.43 \%$ \\
\hline $2012-2013$ & 453,017 & 382,824 & 295,705 & 576,559 & $1,708,105$ & $26.52 \%$ & $22.41 \%$ & $17.31 \%$ & $33.75 \%$ \\
\hline $2013-2014$ & 436,374 & 365,115 & 255,250 & 542,017 & $1,598,756$ & $27.29 \%$ & $22.84 \%$ & $15.97 \%$ & $33.90 \%$ \\
\hline $2014-2015$ & 421,001 & 373,146 & 228,854 & 492,091 & $1,515,092$ & $27.79 \%$ & $24.63 \%$ & $15.10 \%$ & $32.48 \%$ \\
\hline $2015-2016$ & 403,780 & 378,989 & 251,018 & 492,091 & $1,525,878$ & $26.46 \%$ & $24.84 \%$ & $16.45 \%$ & $32.25 \%$ \\
\hline
\end{tabular}

In each of the years covered, more than $32 \%$ of students who enrolled in programs separated without advancing a level, a yearly average of nearly 559,000 people. This means more individuals left their program without advancing a level than stayed in the program and advanced, and nearly twice as many left without advancing compared to those who separated after advancing. In addition, students who completed a level and left might actually represent a mixed result. While advancing a level is positive, many students enroll in adult education program needing to advance through multiple levels to reach their goals (Comings, 2009). Separating after a single level change may leave a learner well-short of their final desired location.

Looking at the percentage of students who leave programs without advancing a level at the individual state level suggests that students in some locations experience more of a churn than others. Over the same six-year period, states (along with DC) can be grouped in the following way according to their average percentage of students leaving without advancing a level.

\section{Avg. \% Separate Without Level Change 2010-2015}

More than 50\% - 10

HI (65\%), SC (62\%), NM (59\%), OK (58\%), NJ (57\%), DC (54\%), MT (54\%), NV (54\%), FL (52\%), OR (50\%

More than 40\% - 16

PA (49\%), WY (49\%), AR (48\%), SD (48\%), ND (48\%), WI (48\%), MI (47\%), ID (47\%), NE (46\%), IN (45\%), AL (45\%), MD (44\%), TN (43\%), MN (42\%), LA (41\%), LA (41\%), GA (40\%)

More than 30\% - 19

WV ( 39\%), CT (38\%), (UT 37\%), CO (37\%), ME (37\%), AK (37\%), KY (37\%), RI (36\%), NC (35\%), KS (35\%), WA (35\%), IL (34\%), MS (33\%), MO (32\%), AZ (31\%), DE (31\%), VT (30\%), VA (30\%), IA (30\%)

Less than $30 \%-6$

MA (21\%), OH (21\%), NY (17\%), NH (16\%), CA (15\%), TX (8\%) 
As can be seen, it is not the case that there are several large outlier states where such a large percentage leave without advancing that it skews the national average. Rather, there are only six states that are below the national average of $33 \%$. In over half the states, at least $40 \%$ of those who enroll in programs do not advance before separating and in 10 , more than $50 \%$ of students do the same. Future research should examine how Texas manages to only have $8 \%$ of students leave without advancing, roughly $1 / 4$ of the national average and almost half as much as the nearest state in terms of this outcome (CA, 15\%).

Although it is true that you don't have to be in a formal program to learn or develop new literacy practices (Reder, 2009), that is the stated goal of the $\mathrm{ABE}$ system itself and why it funds programs across the country. To be clear, programs do show evidence of helping a certain percentage of people attain their goals, but as presently constituted the system is not working for large numbers of people who looked to formal education as a means to increase their literacy skills or educational level. Adult literacy activists have long suggested that the system needs to expand since it only serves a small fraction (possibly less than 2\%) of the 93 million adults who would benefit from instruction (e.g., National Coalition for Literacy, 2009). Given both this gap in services and churn in participation, it is not surprising that across three large assessments of adult literacy skills (International Adult Literacy Survey, 1994-1998; National Assessment of Adult Literacy, 2003-2008, Programme for the International Assessment of Adult Competencies, 2012-2014), average scores in the United States have barely changed. What is the purpose of a system that does not seem to be making progress?

\section{The Nature of the Churn}

Of course, one reason that a learner may leave a program before completing a level is that they decide that it is the best course of action at the time. Comings (2009) refers to this as "stopping out" (in contrast to "dropping out") to highlight the fact that adults make informed decisions about what to do with their time and resources. This approach recognizes that students may cycle in and out of programs according to whether or not their educational goals and life circumstances are aligned. For example, a student may decide to stop-out of their studies in order to spend time on a family issue, they may experience changes in work status or schedule that make attending class difficult or they may develop a serious health issue that prevents them from studying in a program. Although this this type of analysis emphasizes students' choices, for many stopping-out might be final, rather than temporary. In fact, learners who leave their programs often think they cannot return (Comings, 2009).

Studies of learner persistence have identified structures that programs can put in place to reduce the number of students stopping-out and to support their re-entry into programs when they want to come back. Tracy-Mumford (as cited in Comings, 2009) notes that in addition to doing a better job of connecting content and instruction to learners' goals and preferences, programs should address the barriers noted above (e.g., child care, transportation) and need to have adequate counseling services. However, most programs are not equipped to deal with these kinds of situational barriers (Mezirow, Darkenwald \& Knox, 1975; Quigley, 1997) and funds to address them are not included in federal grants. In fact, although the federal budget for adult education has increased across the decades, the amount of per student support has not seen a concomitant increase due to inflation and a larger number of students going through programs. 
For example, the \$67 per student spent in 1969 (United States Department of Education, 2103) was actually worth more than the $\$ 370$ spent per student in 2015 - only \$56 in 1969 dollars. Recent cuts in both the federal and state funding (Foster \& McClendon, 2012) make the introduction of supports that reduce or remove situational barriers even harder for programs to take on.

Although lack of child care, transportation or heath care may indeed lead a student to stopout, the term may unintentionally obscure how the lack of support made the decision nearly inevitable. The difficulty of removing situational barriers should not mean that the adult learner is asked to bear the full responsibility for staying, leaving or cycling in and out of a program. For example, researchers looking at racial disparities in high school disciplinary actions have suggested that Black and Latinx students who discontinue their schooling should be thought of as being "pushed out" rather than "dropping out" (Foster, 2015). These students are the target of policies that make their lived experience of school untenable, so while they may ultimately be the ones making the decision to leave, in some crucial ways their hand was forced. Describing these students as being pushed out helps shift the focus to the system that created the conditions for the decision to leave. Although most adult education programs do not directly participate in the same school to prison pipeline (one reason that high school students are pushed out), by not providing the type of support learners need to continue their studies the system is creating conditions that lead learners to conclude that leaving their program is their best current option.

In addition to limited funding for essential support services, the churn may exist because there are incentives for programs to anticipate and benefit from a certain number of students separating before they have advanced a level. Given the fact that many adult learners do not stay in their classes, programs are faced with a dilemma. They can enroll the number of students called for in whatever contract they have and then worry about how many will be left when it comes time to post-test (an NRS requirement), or overenroll the class with the understanding that not all of the students will make it. Directors of several large adult literacy programs in New Jersey informed me that from their perspective, the overenrolling strategy is the only logical one because if they began with the numbers of students they agreed to provide services to they would never meet their contractual expectations. Each class thus begins with the understanding that many students will not complete it. Treating this expected drop-off as standard operation procedure reduces the pressure on programs to identify ways to help all students who enroll to remain in their classes.

Furthermore, programs may actually benefit financially from a student who stops out after they have spent enough time in their course to count towards NRS reporting. Once funds are encumbered, they do not have to be returned if the student is no longer enrolled. These funds continue to support program infrastructure, keeping the per student cost manageable. Of course, this does not mean the ABE programs do not take their educational commitments seriously. Rather, their funding structure militates against them taking consistent and effective action to prevent stopping or dropping out. As part of an analysis of the adult literacy system in New Jersey, multiple programs reported that because of the way reimbursements for services are structured, it is fiscally impossible for them to retain students for very long. They suggested that at a certain point their program is compelled to ask a given student to leave (or go 
back on the waiting list) so that they can enroll a new student and encumber new funds (Jacobson, 2013). If and when the individual who was forcibly exited returns to the program, they will technically be a new student and have new funds associated with them. In this way, enrollment is managed with an eye on the bottom-line rather than on educational progress. Most other programs may not be as open or explicit about their process of pushing out students, but they also participate in, and rely on, the churn these enrollment and funding policies create. It is difficult to estimate how widespread this practice is because programs who volunteer this kind of information put themselves at risk of additional scrutiny. However, without transparency in the ways that funding works in practice, it is likely that there will continue to be both official and unofficial means of program maintenance. This triage-like approach to funding means administrators need to be able to finesse the system, which is not efficient or sustainable, and makes programs themselves vulnerable to closure.

What is the purpose of a system in which a disruptive churn appears to be standard operating procedure? In their study of welfare provision in the United States, Piven and Cloward (1993) detail how people looking for support are faced with long waiting lists that lead them to give up trying to get assistance. They also report that it is common for eligible applicants to be denied, forcing them reapply and face those same long waiting lists. Piven and Cloward (1993) suggest that the ways in which welfare is provided or withheld during certain periods of time and for certain populations functions as a means of regulating the behavior and expectations of the poor. They suggest that this churning process is made intentionally difficult and capricious in order to make any job, regardless of the pay, attractive. The key message - better a bad job than having to deal with the welfare system. In this way, the provision of support operates in conjunction with the needs of capital for compliant workers. The structure of the system is designed to teach recipients their place and to limit the type of support they can expect. How long can ABE students be expected to stay on a waiting list hoping to get a spot in a classroom? How would it feel to finally be in a class only to then need to stop-out because barriers arise?

A similar disempowering churn has been identified in the functioning of employment agencies. Arsdale (2016) notes that people who find work through these agencies are often shuffled in and out of various positions, consistently vulnerable to the actions of others who may not have their best interests in mind. He describes one common scheme as follows. Because agencies collect fees from the workers for the job placement, some unscrupulous agencies scheme with employers to have these new workers fired after a certain point, necessitating the placement of a new worker who will also have to pay a placement fee. The original worker must then go back to the agency to start the exploitative process all over again. A student who has been pushed out of an ABE program to make room for a new student who will bring newly encumbered funds will recognize the steps of this cycle, even if the motivation is less nefarious.

Additional insights can be gathered by examining how the crisis in housing vulnerability has been addressed. Willse (2015) notes that because the mental health and behavior of individuals who experience housing vulnerability has dominated discussions, "what to do about the homeless, rather than what to do about housing, has become the obsession of government policy, social service practice, and social scientific inquiry" (pg. 54). In this way, structural questions about housing 
vulnerability are not examined, and the ways in which the distribution of resources creates the possibility of homelessness is ignored (e.g., the fact that there are vast number of homes and apartments that sit unoccupied). For this reason, Willse (2015) suggest that the real goal is "the management of homelessness, rather than the eradication of housing vulnerability" (p. 55). Individuals cycle in and out of temporary housing, facing the same daunting barrier to getting and keeping services that Piven and Cloward (1993) describe. In addition, Willse (2015) goes on to detail how the job of managing this cycle of vulnerability can be a lucrative one for large nonprofits who "serve" the homeless but don't reduce housing vulnerability. The potential parallels here to adult literacy are striking. As noted above, over multiple decades in which the federal government has allocated funds for adult literacy provision, the average skills of the population have not changed. Rather than easing at all towards eradication, literacy issues would appear to be managed, at best, by the federal government and numerous non-profit organizations.

It is not surprising that there are profits to be made from creating and sustaining the churns noted above. In recent times, the process by which eligible people are denied aid (Piven a\& Cloward, 1993) has been modernized and monetized for the digital age. In her examination of the use of automated systems to determine eligibility for welfare and health care, Eubanks (2017) explains that these systems continue to generate incorrect determinations that prevent people in need from getting necessary support. These "mistakes" are difficulty for individuals to rectify, so incorrect determinations of ineligibility help reduce the welfare rolls and keep the state's health care expenses down. The companies that create and manage these automated systems are paid well by states, and Piven and Cloward (1993) suggest there has long been money available to investigate if the poor are paying their taxes or receiving the "appropriate" amount of welfare (Ulrich, 2019).

With regards to adult literacy, the churn in participation is in part created by programs straining to meet the demands of such investigation in the form of the NRS. This elaborate and expensive accountability system, created and managed by contractors, has staff at multiple levels of government who are paid to track how that $\$ 370$ per student funding is being spent. Contrast this to Defense Department procurement procedures that have allowed the Pentagon to accrue \$21 trillion worth of financial transactions for which it has no documentation (Lindorff, 2018). It is unclear how the NRS data is being used to improve outcomes data is being used to increase outcomes or to reduce the number of people who move through the system without making progress. For that reason, the real point appears to be the act of publicly tracking adult learners.

\section{Implications}

As a means of increasing positive outcomes, ABE research and advocacy has typically focused on identifying best practices in instruction. These "what works" studies look at classroom level issues and are useful for tailoring instruction to meet the needs of students and to maximize the benefit of their time in programs. However, studies hoping to find whether "this method works better than that" (Reder, personal communication, 2017) are likely to have limited effectiveness in the face of a system that has hundreds of thousands of students leave their programs before they complete a level. A full revisioning of $\mathrm{ABE}$ is necessary and below are three suggestions for moving forward.

\section{Examine the Current System}


The present study is preliminary in nature and requires additional work to provide necessary nuance and complexity. A key issue is the variety of program types within the ABE system.

It is likely that different types of programs experience distinct types of educational churn. For example, the policies in place at a communitybased adult literacy organization might contrast sharply with those at a community college offering English as a Second Language. Should read: Another issue is the nature of federal and state ABE bureaucracies. Future research should identify patterns in official and unofficial resource allocation and their impact on the functioning of the system. For example, what amount of money is spent at each level of the system on administration and accountability procedures? Without a more detailed accounting of how the system is currently working it will be difficult to suggest specific changes in policy to prevent students from being pushed out to keep the funding process running smoothly.

In addition, the connection between the ABE system and other social welfare programs must be better understood. In general, within the field of $A B E$ research detailed examinations of the situational barriers facing learners have been bracketed off and left to those working in other areas, such as mental health, housing, or domestic violence prevention. Although those have traditionally been topics of ABE lessons in programs with a social justice orientation, it often stops there. Explicit and sustained alliances between diverse groups of activists and engaged researchers could more productively address unequal distribution of resources at the systemic level.

\section{Expand the Critique}

Similar to concerns about the role of K-12 education plays in perpetuating inequality (Bowles
\& Gintis, 2011; Graff,1991), there have been longstanding critiques of the nature of adult literacy and basic education. Learner leader Calvin Miles suggested that, "The adult education system is like a large plantation where the students are kept in place by gatekeepers who believe they are doing the right thing" (as cited in Green, 2015, p. 43). Formal education here is understood as potentially reigning in or domesticating learners' desire for freedom and justice and reducing their ability to critique their conditions (Macedo, 2006). For example, Sandlin (2004) suggests that the key message of most workforce development programs is that hard work is what determines one's status and economic outcomes (“It's Up to You!") rather than micro or macro-economic forces. As ever, working class students are taught that they get what they deserve.

In addition to critiquing the role that curriculum and instruction play in disciplining adult learners, students and teachers should collaboratively investigate the messages the ABE system sends by having a consistent churn at its heart. Teachers can invite discussion of the ways resource allocation, accountability regimes, and funding policy serve to push students out of the very programs they waited patiently to enroll in. Consistent with the experiences of those looking for other types of support, the whole process of enrolling in and leaving programs may be structured to regulate the behavior of those wanting to access education. Students are simultaneously told "it is up to you!" while having their agency circumscribed by structural inequalities. Building on productive experiences of discussing issues like mental health, classwork can include identifying the ways the $\mathrm{ABE}$ system perpetuates discourses about merit, expectations and personal responsibility that seek to naturalize economic hierarchies.

Although it is common for activists to speak on 
behalf of the "marginalized," this terminology is often problematic. In fact, though some communities may exist on the periphery spatially, functionally they are at the heart of oppressive and exploitative networks (Freire \& Macedo, 1987). For example, those laboring for below life-sustaining wages may not have a voice when economic policy is being determined, but the capitalist system they work in would not function without them. In the same way, those who decide to participate in the adult education system but then separate before reaching their goals need to be understood as central to the functioning of the system, and any assessments of the impact of the system should include their experience.

\section{Explore Other Models}

Activists are understandably concerned about the fact that federal funding for the ABE in the United Sates is vulnerable to shifts in political orientation and will, and they often need to rally students, teachers and their allies to lobby their representatives to push back against proposed cuts. When cuts are avoided, the field celebrates. Likewise, when minor increases in funding are offered, the field also celebrates. This pattern has repeated itself for decades. In this way, supporters of adult literacy and basic education are kept busy treading water. The perpetual push back against funding cuts and calls for piecemeal increases leads to the nature of the system being unquestioned - a system that does not provide the necessary resources for students to succeed, that does not enable most ABE students to successfully transition into higher education (Jacobson, 2016), that does not move people beyond poverty wages (Jacobson, 2016) and that has massive amounts of people cycling in and out of it. Given the size of the problem and the current structure of the system, requests for increases of $\$ 10$ million or so are unlikely to have much of an impact at the broader level. Increasing the ABE student population by tens of thousands would only be working on the margins and do little to stop the larger churn or increase the literacy skills of large segments of the population.

Instead of providing triage to a system that is providing benefits to only a select segment of adult learners, a total rethinking of the structure is necessary. For example, in the short term, to reduce the likelihood that learners will feel compelled to stop out because of situational barriers, adequate support services (e.g., child care, transportation, counseling) must be understood to be a required part of any $\mathrm{ABE}$ system. States are currently expected to create integrated workforce development systems that bring together ABE providers, One Stop Centers, community colleges and local employers to ease the transition from one step to the next. That same level of coordinated services should be provided to all learners, not just those looking for work or career training. For this to be effective, rather than being tracked as part of disciplinary accountability schemes, students need to be consulted. Their educational programs should be built with them instead of for them. The level of funding necessary would be far beyond the modest requests put forth by adult literacy activists. Rather than via piecemeal requests for modifications, systemic improvement requires a holistic educational and social services project along the lines of the proposed Green New Deal.

Finally, to move forward the field might have to take a look backward. Re-examining the type of large-scale adult literacy mobilizations that took place in countries like Cuba, Nicaragua, and Guinea Bissau may provide lessons for the contemporary United States. Rather than offering examples of specific classroom methodologies, such as generative codes (Freire, 1970), these 
national adult literacy campaigns could provide insight into how best to assess the impact of educational programing at the societal level. Similarly, it will be helpful to revisit the history of labor colleges established in the United States in the 1920s and 1930s (Altenbaugh, 1990). These projects were an attempt to provide the education seen as necessary for successful labor struggles. Rather than working within an existing system developed and funded by the government in coordination with capital, workers created their own educational institutions. These labor colleges, like the national literacy campaigns noted above, can be understood as "a political project with pedagogical implications, not a pedagogical project with political implications" (Brookfield \& Holst, 2011, pg. 78). Given the vulnerable and exploited conditions of adult learners stuck in coalescing churns, it is just such a political project that is required. 


\section{References}

Altenbaugh, R. (1990). Education for struggle: The American Labor colleges of the 1920s and 1930s. Philadelphia, PA: Temple University Press.

Arsdale, D. (2016). The poverty of work. Chicago, IL: Haymarket Books.

Becker, W. J., Wesselius, F. \& Fallon, R. (1976). Adult basic education follow-up study, 1973-75. Kenosha, WI: Gateway Technical Institute.

Beder, H. (1999). The outcomes and impacts of adult literacy education in the United States. Cambridge, MA: The National Center for the Study of Adult Learning and Literacy.

Bowles, S. \& Gintis, H. (2011). Schooling in capitalist America. Chicago, IL: Haymarket Books.

Brookfield, S. \& Holst, J. (2011). Radicalizing learning. San Francisco, CA: Jossey-Bass.

Comings, J. (2009). Student persistence in adult literacy and numeracy programs. In S. Reder and J. Bynner (Eds.), Tracking adult literacy and numeracy skills (pp. $160-$ 176). New York, NY: Routledge.

Eubanks, V. (2017). Automating inequality. New York, NY: St. Martin's Press.

Foster, K. (2015). "Pushed out of school for being me." New York City's struggle to include youth and community voices in school discipline reform. Voices in Urban Education, 42, 43-49.

Foster, M., \& McClendon, L. (2012). Sinking or swimming: Findings from a survey of state adult education tuition and financing policies. Washington, DC: Center for Law and Social Policy.

Freire, P. (1970). Pedagogy of the oppressed. M. Ramos (Trans). New York, NY: Continuum.

Freire, P. \& Macedo, D. (1987). Literacy: Reading the word and the world. Westport, CT: Bergin and Garvey.

Green, D. (2015). Unfit to be a slave: A guide to adult education for liberation. Boston, MA: Sense Publishers.
Graff, H. (1991). The literacy myth. New Brunswick, NJ: Transaction.

Jacobson, E. (2013). Investing in New Jersey's adult learners. Trenton, NJ: State Council on Adult Literacy Education Services, New Jersey.

Jacobson, E. (2016). Workforce rhetoric and the realities of 21 st century capitalism. Literacy and Numeracy Studies, 24, 1. )

Lindorff, D. (2018, November 27). The Pentagon's massive accounting fraud exposed. The Nation. Retrieved from https://www.thenation.com/article/pentagon-auditbudget-fraud/

Macedo, D. (2006). Literacies of power. Boulder, CO: Westview Press

McFarland, J., Cui, J., Rathbun, A., \& Holmes, J. (2018). Trends in high school dropout and completion rates in the United States: 2018 (NCES 2019-117). U.S. Department of Education. Washington, DC: National Center for Education Statistics. Retrieved from http://nces.ed.gov/pubsearch.

Merrifield, J., Smith, M., Rea, K., \& Shriver, T. (1994). Longitudinal study of adult literacy participants in Tennessee: Year two report. Knoxville, TN: Center for Literacy Studies, University of Tennessee.

National Center for Educational Statistics (ND). PIAAC 2012/2104 Results. Retrieved from https://nces.ed.gov/ surveys/piaac/results/summary.aspx

Mezirow, J., Darkenwald, G. \& Knox, A. (1975). Last gamble on education: Dynamics of adult basic Education. Washington, DC: Office of Education.

National Coalition for Literacy (2009). Adult literacy fact sheet. Washington, DC.

Piven, F. F. \& Cloward, R. (1993). Regulating the poor: The functions of public welfare. New York, NY: Vintage.

Purcell-Gates, V., Degener, S., Jacobson, E., \& Soler, M. (2002). The impact of authentic adult literacy instruction on adult literacy practices. Reading Research Quarterly, 37(1), 70 - 92. 
Quigley, A. (1997). Rethinking literacy education: The critical need for practiced base change. San-Francisco, CA: Jossey-Bass.

Reder, S. (2009). The development of literacy and numeracy in adult life. In S. Reder and J. Bynner (Eds.), Tracking adult literacy and numeracy skills (pp. 59 - 84). New York, NY: Routledge.

Sandlin, J. (2004). "It's all up to you": How welfare to work educational programs construct workforce success. Adult Education Quarterly, 54, 2, 89-104.

St. Pierre, R. Swartz, J. Murray, S., Deck, D. \& Nickel, P. (1993). National evaluation of Even Start Literacy Program: Final report. Washington, DC: U.S. Department of Education, Office of Policy and Planning.

Ulrich, R. (2019). Why is the IRS auditing the poor more than the rich? The American Prospect. Retrieved from https:// prospect.org/article/why-irs-auditing-poor-more-rich

U.S. Department of Education (2005). A first look at the literacy of America's adults in the $21^{\text {st }}$ century. Washington, DC: Author.

U.S. Department of Education, Office of Vocational and Adult Education (2013). Federal adult education: A legislative history 1964-2013. Washington, DC: Author.
U.S. Department of Education, Office of Career, Technical, and Adult Education (2015) Adult Education and Family Literacy Act of 1998: Annual report to Congress, program year 2011-12. Washington, DC: Author.

U.S. Department of Education, Office of Career, Technical, and Adult Education (2016). Adult Education and Family Literacy Act of 1998: Annual report to Congress, program year 2012-13. Washington, DC: Author.

U.S. Department of Education, Office of Career, Technical, and Adult Education (2018a). Adult Education and Family Literacy Act of 1998: Annual report to Congress, program year 2013-14: Washington, DC: Author

U.S. Department of Education, Office of Career, Technical, and Adult Education (2018b). Adult Education and Family Literacy Act of 1998: Annual report to Congress, program year 2014-15. Washington, DC: Author.

U.S. Department of Education, Office of Career, Technical, and Adult Education (2018c). Adult Education and Family Literacy Act of 1998: Annual report to Congress, program year 2015-16. Washington, DC: Author.

Willse, C. (2015). The value of homelessness. Minneapolis, MN: University of Minnesota Press. 